\title{
Retraction Note: Melatonin promotes angiogenesis during repair of bone defects: a radiological and histomorphometric study in rabbit tibiae
}

\author{
María Piedad Ramírez-Fernández ${ }^{1}$. José Luis Calvo-Guirado ${ }^{1}$. José Eduardo-Maté Sánchez de-Val ${ }^{2}$. \\ Rafael Arcesio Delgado-Ruiz ${ }^{2}$ - Bruno Negri ${ }^{1}$. Guillermo Pardo-Zamora ${ }^{1}$. David Peñarrocha ${ }^{3}$. Cristina Barona ${ }^{4}$. \\ Jose Manuel Granero' ${ }^{1}$ Miguel Alcaraz-Baños ${ }^{5}$
}

Published online: 3 January 2022

(c) Springer-Verlag GmbH Germany, part of Springer Nature 2021

\section{Retraction Note: Clin Oral Invest (2013) 17:147-158 https://doi.org/10.1007/s00784-012-0684-6}

The Editor in Chief retracted this article because of significant concerns regarding a number of Figures presented in this work, which question the integrity of the data. After publication, overlap was detected with figures in other articles published by these authors, but with different labels. Specifically,

Figure $2 \mathrm{~A}$ is described as control group at 1 week. It appears the same image was used in (1, now retracted) and described as control group at 1 month.

Figure $2 \mathrm{~B}$ is described as Melatonin group at 1 week. It appears the same image was used in (2, now retracted) and described as control group at 3 months.

Figure $2 \mathrm{~F}$ is described as melatonin group at 3 weeks. It appears the same image was used in (2, now retracted) and described as control group at 4 months.

The original article can be found online at https://doi.org/10.1007/ s00784-012-0684-6.

María Piedad Ramírez-Fernández

mpramirezfern@hotmail.com

1 Department of Implant Dentistry, Faculty of Medicine and Dentistry, University of Murcia, Hospital Morales Meseguer, Marqués de los Vélez, s/n, 30008, Murcia, Spain

2 Department of Restorative Dentistry, Faculty of Medicine and Dentistry, University of Murcia, Murcia, Spain

3 Master of Oral Surgery and Implantology, University of Valencia, Valencia, Spain

4 Department of Oral Surgery, the Complutense University of Madrid, Madrid, Spain

5 Department of Radiology and Physical Medicine, Faculty of Medicine and Dentistry, University of Murcia, Murcia, Spain
Figure 5C is described as control group at 2 weeks, but it appears to be from the same histological section as Figure 5D (stained with trichrome) which is purported to be from an animal in different group. It appears the same image was used with different labels in (3, now retracted; 4 , now retracted; 5 , now retracted and 6 , now retracted).

Figure 5D is described as melatonin group at 2 weeks. It appears the same image was used with different labels in (2, now retracted and 7 , now retracted).

Figure $5 \mathrm{H}$ is described as melatonin group at 4 weeks. It appears the same image was used with different labels in (2, now retracted and 5 , now retracted).

Figure 6A - it appears the same image was used with different labels in (1, now retracted and 2, now retracted).

Figure 6D - it appears the same image was used with different labels (1, now retracted,4, now retracted and 9, now retracted).

Figure 6E - it appears the same image was used with different labels (2, now retracted and 4, now retracted and 8, now retracted).

Figure $6 \mathrm{~F}$ - it appears the same image was used with different labels (4, now retracted and 9, now retracted).

Figure 6G- it appears the same images were used with a different label in (2, now retracted).

Figure $6 \mathrm{H}$ - it appears the same images were used with a different label in (1, now retracted).

The Editor-in-Chief therefore no longer has confidence in the integrity of the data in this article.

David Peñarrocha Oltra agrees to this retraction. María Piedad Ramírez-Fernández, José Luis Calvo-Guirado, José Eduardo-Maté Sánchez de-Val, Rafael Arcesio 
Delgado-Ruiz, Bruno Negri, Guillermo Pardo-Zamora, Cristina Barona, Jose Manuel Granero \& Miguel Alcaraz-Baños have not responded to any correspondence from the editor or publisher about this retraction.

\section{References}

1) (RETRACTED) Ramírez-Fernández, M.P., Calvo-Guirado, J.L, Delgado-Ruiz, R.A., José Eduardo Maté-Sánchez del Val, J.E., Gómez-Moreno, G., Guardia, J., Experimental model of bone response to xenografts of bovine origin (Endobon $\left.{ }^{\circledR}\right)$ : a radiological and histomorphometric study. Clin. Oral Impl. Res. 22, 2011; 727-734. https://doi.org/10.1111/j.1600-0501.2010.02052.x

2) (RETRACTED) Calvo-Guirado, J.L et.al. Experimental Model of Bone Response to Collagenized Xenografts of Porcine Origin (OsteoBiol@ mp3): A Radiological and Histomorphometric Study. Clinical Implant Dentistry Related Research 15, 2013, 143 151 https://doi.org/10.1111/j.1708-8208.2011.00337.x

3) (RETRACTED) De Aza, P., Mate-Sanchez de Val, J.E., Baudin, C., Albacete-Martínez, C.P., Armijo Salto, A., Calvo-Guirado, J.L., Bone neoformation of a novel porous resorbable Si-Ca-P-based ceramic with osteoconductive properties: physical and mechanical characterization, histological and histomorphometric study. Clin. Oral Impl. Res. 27, 2016, 1368-1375 https://doi.org/10.1111/clr.12745

4) (RETRACTED) Calvo-Guirado, J.L et.al. Melatonin stimulates the growth of new bone around implants in the tibia of rabbits.
J. Pineal Res. 2010; 49:356-363 https://doi.org/10.1111/j.1600079X.2010.00801.X

5) (RETRACTED) Calvo-Guirado, J.L et.al. New bone formation in bone defects after melatonin and porcine bone grafts: experimental study in rabbits. Clin. Oral Impl. Res. 26, 2015, 399-406, https://doi.org/10.1111/clr.12364

6) (RETRACTED) Maté-Sánchez del Val, J.E. et al. nvivo behavior of hydroxyapatite/b-TCP/collagen scaffold inanimal model. Histological, histomorphometrical,radiological, and SEM analysis at 15, 30, and 60 days.Clin. Oral Impl. Res. 00, 2015, 000-000 https://doi.org/10.1111/clr.12656

7) (RETRACTED) Ramírez-Fernández, M.P., et. al. Bone response to hydroxyapatites with open porosity of animal origin (porcine [OsteoBiol $\left.{ }^{\circledR} \mathrm{mp} 3\right]$ and bovine [Endobon $\left.{ }^{\circledR}\right]$ ): a radiological and histomorphometric study. Clin. Oral Impl. Res. 22, 2011; 767773. https://doi.org/10.1111/j.1600-0501.2010.02058.x

8) (RETRACTED) Calvo-Guirado, J.L et.al. Enhanced bone regeneration with a novel synthetic bone substitute in combination with a new natural cross-linked collagen membrane: radiographic and histomorphometric study. Clin. Oral Impl. Res. 26, 2015, 454-464 https://doi.org/10.1111/clr.12399

9) (RETRACTED) Calvo-Guirado, J.L et.al. Influence of Biphasic $\beta$-TCP with and without the use of collagen membranes on bone healing of surgically critical size defects. A radiological, histological, and histomorphometric study. Clin. Oral Impl. Res. 25, 2014, 1228-1238 https://doi.org/10.1111/clr.12258

Publisher's note Springer Nature remains neutral with regard to jurisdictional claims in published maps and institutional affiliations. 